\title{
Chimpanzés não amam! Em defesa do significado
}

\author{
Eliane Sebeika Rapchan \& Walter Alves Neves \\ Professora do Departamento de Ciências Sociais - UEM/PR \\ Professor do Departamento de Genética e Biologia Evolutiva - IB/USP
}

RESUMO: O texto é uma reflexão crítica sobre o artigo "Chimpanzés também amam: a linguagem das emoções na ordem dos primatas" de Eunice R. Durham. Trata-se de uma rara oportunidade para discutir as contribuições recentes da ecologia evolutiva humana, etologia, neurobiologia, primatologia, psicologia evolutiva e sociobiologia, da ótica da produção de significados diante das questôes postas sobre as emoções em grandes símios. O recorte proposto contempla uma ampla gama de questões: da problematização das representações produzidas por pesquisadores dedicados ao estudo do comportamento animal à produção de um balanço sobre as possibilidades e os limites das capacidades simbólicas dos chimpanzés. Tal exercício caracteriza-se, portanto, por ser uma avaliação do estado da arte no que se refere às interações entre consciência, cognição, produção simbólica e sentimentos.

PALAVRAS-CHAVE: chimpanzé, emoções, evolução, sentimentos, símbolo.

\section{Introdução}

A iniciativa de Durham (2003) na publicação de "Chimpanzés também amam: a linguagem das emoções na ordem dos primatas" foi recebida com otimismo pelos pesquisadores brasileiros envolvidos com temas correlatos, dado que, apesar dos questionamentos radicais que os estu- 
Eliane S. Rapchan \& Walter A. Neves. Chimpanzés não amam!

dos sobre o comportamento de grandes símios, particularmente chimpanzés, têm colocado para as ciências sociais, há pouquíssimos antropólogos sociais ou culturais no Brasil dispostos a sequer pensar no assunto.

Por isso o texto, em princípio, sinaliza uma possibilidade de expansão de horizontes em direção à formação de uma interface entre disciplinas, considerando a necessidade de a antropologia e a psicanálise incorporarem resultados de pesquisas sobre comportamento produzidos por outras áreas (Durham, 2003, p. 113 e 115), como a importância das relações triangulares, via siblings, estabelecidas entre a mãe chimpanzé, seu filhote desmamado e o recém-nascido (id., p. 133-34).

Entretanto, a despeito de seus aspectos aparentemente positivos, é imprescindível escrutinar criticamente o artigo de Durham (2003) pelo fato de ele não contemplar, entre outras omissōes, reflexões sobre a ontologia da produção de sentidos, justamente no aspecto escolhido como eixo central da discussão: "os sentimentos dos chimpanzés".

Com tal objetivo, este artigo divide-se em três segmentos. O primeiro faz um balanço sobre as relações entre sentimentos e biociências, contrapondo reflexōes gerais sobre o texto em questão; o segundo pretende demonstrar que as posiçôes da autora localizam-se muito aquém do debate sobre o assunto; e o terceiro discute os pontos em que a autora situa-se além do debate, quando ela aponta perspectivas e conclusões que, no entanto, extrapolam os resultados das pesquisas publicadas.

\section{Questões gerais: sentimentos e biociências}

O complexo problema das relações entre emoções, evolução e semelhanças entre espécies remonta a Charles Darwin (2001). Em A expressão das emoções no homem e nos animais, Darwin assinalou três aspectos centrais dos problemas que serão retomados aqui, com base em debates 
Revista de Antropologia, São Paulo, USP, 2005, v. 48 no 2.

que nos são contemporâneos: a existência de semelhanças de fundo biológico entre humanos e animais (Darwin abordou semelhanças entre músculos faciais e expressões faciais de humanos e de outros primatas); o caráter evolutivo de expressões como o arrepiar de pêlos e cabelos diante do terror; e as dificuldades no estudo da expressão das emoções devido à sua sutileza e aos limites na capacidade de objetivação, dado seu forte potencial em estimular a simpatia e a imaginação do observador (Darwin, 2001).

Os pesquisadores que se dedicam ao estudo do comportamento animal têm promovido há décadas debates acirrados sobre a legitimidade da antropomorfização na caracterização do comportamento de outras espécies. Waal (2005), aliás, apresentou, no número da Nature dedicado ao genoma chimpanzé, um balanço sobre o quanto o que sabemos sobre essas criaturas e o que sentimos por elas mudaram no último século.

Em 1946, Donald Olding Hebb observou que os tratadores que usavam atributos psicológicos para descrever certos comportamentos animais eram mais eficientes em predizer suas condutas do que os cientistas que se valiam de terminologias mais "objetivas", ou seja, mais descritivas e menos antropomórficas (Mitchell \& Hamm, 1997). Com base nisso, Hebb propôs um vocabulário descritivo e antropomórfico, associando o registro, passo a passo, do comportamento animal às situaçóes e aos contextos em que ocorreu.

Em contrapartida, os primeiros trabalhos de Jane Goodall (1965) receberam duras críticas por sua iniciativa em adotar nomes, termos humanos de parentesco e contar histórias de vida associadas à apresentação de dados sobre os chimpanzés de Gombe. Tudo isso parecia muito pouco científico. À mesma época, Desmond Morris (1967) apontou os riscos da humanização do comportamento dos grandes símios, provocada justamente pela grande proximidade evolutiva desses grandes primatas com os humanos. 
Segundo Morris, se um pesquisador identifica uma expressão facial como "feroz", ele próprio tende a se convencer dessa ferocidade como verdadeira e dificilmente irá descartá-la, comprometendo a compreensão do comportamento do animal. Para Morris, os primatas não humanos possuem expressões faciais agressivas, mas elas são semelhantes e não idênticas às humanas. Por essa ótica, o risco desse tipo de associação é real, e o pesquisador deve estar sempre vigilante, procurando manter o equilíbrio em seus registros quanto a semelhanças e diferenças.

Há 30 anos surgiram novas divergências com relação às dimensões "subjetivas" nas pesquisas sobre o comportamento de primatas sob a influência da sociobiologia e da ecologia comportamental evolutiva, resultando no abandono de influências da antropologia social que se manifestaram por iniciativa de Washburn (Kuper, 1994; Rapchan, 2005) nos trabalhos de Irwing Devore, Jane Goodall e Franz de Waal (Rodman, 1999, p. 314) nos anos 1960. Altmann (apud Hrdy, 2001, p. 64), por exemplo, tem elaborado técnicas para tentar conter os problemas relativos à "predisposição" do observador de primatas em campo aos abusos da humanização dos comportamentos, o que, segundo ela, levaria à distorção dos fenômenos observados.

Em direção oposta, Mitchell e Hamm (1997, p. 176) retomaram a questão do uso da terminologia psicológica dirigida a humanos para a caracterização de outros mamíferos pela via da semelhança física, da familiaridade e da proximidade filogenética. Segundo eles, há estereótipos culturais úteis para caracterizar o comportamento animal e, desde que contextualizados, podem servir tanto como descrição abreviada e compreensível quanto como via de acesso para a incorporação de aspectos objetivos e subjetivos em pesquisas pautadas nas relaçóes entre humanos e não humanos. Mais recentemente, surgiram discussões sobre os diferentes graus de envolvimento pessoal dos primatólogos com os 
grandes símios pelo recorte de gênero (Jahme, 2001) ou pelo tipo de pesquisa desenvolvida (Lestel, 2004).

Tais questôes remetem à importância de se refletir sobre a condução da pesquisa na produção do conhecimento sobre o comportamento de chimpanzés, especialmente quanto ao problema da produção de sentidos por várias perspectivas - desde a existência de capacidade simbólica entre os grandes símios até a interação intensa entre pesquisadores e primatas não humanos, passando pelo problema da atribuição de significados específicos aos comportamentos registrados.

Privilegiando referenciais locais ou universais, a antropologia simbólica produziu reflexôes sobre a produção e a atribuição de significados universais, gerais ou específicos a animais, plantas e fenômenos naturais, ao tempo, aos corpos celestes e lugares, à alteridade e ao mundo natural e social conhecido (Balandier, 1974; Bourdieu, 1989; Geertz, 1978; Lévi-Strauss, 1988; 1993; Mauss, 1974; Sperber, 1978; 1992; Turner, 2005). O ponto de partida deste ensaio estabelece-se justamente no fato de o artigo de Durham (2003) ter ignorado solenemente tais questôes. Durham não define os pontos críticos para uma discussão sobre "sentimentos" de animais de uma perspectiva antropológica e não analisa os aspectos simbólicos desse problema, do mesmo modo que não apresenta definiçôes rigorosas acerca do que são "sentimentos" e "emoções".

Além disso, outro fator a destacar no artigo é o desequilíbrio no tratamento do material selecionado para reflexão. Qualquer exercício comparativo interdisciplinar pressupõe eqüidade das partes, mas não é isso que se encontra no texto. O propósito de Durham é discutir o que as pesquisas sobre o comportamento de chimpanzés já revelaram sobre seus "sentimentos" em comparação aos humanos. Contudo, a autora apresenta um extenso arcabouço de referências a alguns clássicos das ciências sociais, da filosofia e da psicanálise para só então mencionar, quase sempre de modo incompleto e desatualizado, a bibliografia recente so- 
Eliane S. Rapchan \& Walter A. Neves. Chimpanzés não amam!

bre o comportamento de chimpanzés. $\mathrm{O}$ mesmo vale para a ausência de referências às reflexões atuais sobre o tema de antropólogos sociais como Asquith (1995), Ingold (1995; 1996), Kuper (1994; 2000) e Sperber (1985; 2000) ou de um etólogo-filósofo como Lestel (2004).

Os mesmos exercícios intelectuais que permitiram aos pesquisadores registrar e interpretar os "sentimentos amorosos" dos chimpanzés, e que Durham selecionou para sua análise como fatores importantes para a vida social (2003, p. 92), não estão desassociados das abordagens sobre consciência, raciocínio, linguagem, vida social e instrumental simbólico culturalmente construído. Contudo, Durham (id., p. 87) toma estes últimos como divisores de águas entre humanos e não humanos, utilizando como critério a suposta ausência de tais características em grandes símios e ignorando os debates atuais sobre o tema.

Ora, se é possível concordar com a autora quanto suas afirmaçóes implícitas com relação à singularidade humana relativa à produção de símbolos na plenitude de sua complexidade (Mithen, 2002), em todos os demais aspectos a posição de Durham está na contracorrente das diretrizes gerais adotadas pela etologia e primatologia nos últimos 45 anos, e mais enfaticamente nos últimos dez anos. Basta, para isso, observar as reflexões de Ades (1997) sobre a consciência animal ou, ainda, os trabalhos dedicados a chimpanzés e/ou outros primatas que abordam cognição (Cheney \& Seyfarth, 1990; Corbey, 1995; Hoof, 2001; Joulian, 1996; Tomasello, 1997; 1999; Tomasello \& Call, 1997; De Waal, 2001; 2005) ou comunicação e linguagem (Parker \& Gibson, 1994; Rumbaugh, Savage-Rumbaugh \& Sevcik, 2001; Tomasello, 1994).

Para se ter uma idéia da extensão do equívoco da adoção desse divisor de águas como algo já resolvido, basta levantar os registros sobre o comportamento de grandes símios que apresentam informações sobre capacidades sutis rigorosamente registradas ou tomar conhecimento dos debates acalorados sobre as relações entre as capacidades humanas rela- 
Revista de Antropologia, São Paulo, USP, 2005, v. 48 No 2.

cionadas à cognição, cultura e linguagem referidas ao tempo e ao processo evolutivo (Böesch \& Tomasello, 1998; Galef, 1992; Henrich \& McElreath, 2003; Lindly \& Clark, 1990; Savage-Rumbaugh, Fields \& Tagliatela, 2001; Tomasello, 1999, p. 215-17).

Ao mesmo tempo, a justificativa de Durham em favor do forte apelo da abordagem dos "sentimentos" de chimpanzés é facilmente compreensível, pois está associada ao acesso a dados mais sutis sobre comportamento que se soma ao refinamento da sensibilidade dos pesquisadores e à ampliação de sua empatia para com os grandes símios. Todos esses fatores devem ser considerados quando o assunto é a abordagem dos "sentimentos" de chimpanzés. Para compreender o processo, basta observar as duas grandes rupturas ocorridas na história dos estudos do comportamento de primatas diretamente relacionadas à reformulação dos procedimentos e métodos de pesquisa e à mudança na postura dos primatólogos diante dos animais estudados (Rapchan, 2004).

A primeira ruptura corresponde a uma mudança radical no olhar dos primatólogos, que abandonaram definitivamente a perspectiva de que observavam toscos arremedos humanos e descobriram universos próprios de comportamentos complexos (Dukelow, 1999), o que resultou no uso de expressões outrora válidas apenas para os humanos: cognição, cultura, tradição, relações sociais e comunitárias, parentesco, poder, status e outras para descrever comportamentos ou aspectos da vida coletiva desses animais. Vale lembrar que os resultados obtidos pela primatologia associados aos avanços nas técnicas de mapeamento genético e a outras disciplinas ressuscitaram o debate sobre as fronteiras entre evolução e comportamento humano. A segunda ruptura diz respeito ao estabelecimento de vínculos intensos, compromissos e sentimentos de responsabilidade que os pesquisadores desenvolveram com relação aos primatas, o que levaria muitos à militância conservacionista (Dukelow, 1999; Jahme, 2001; Rapchan, 2004). 
Eliane S. Rapchan \& Walter A. Neves. Chimpanzés não amam!

Outra consequiência desse processo refere-se às opções metodológicas acerca da coleta e do registro de dados. Trabalhos de campo prolongados, continuados e minuciosos estimularam o caráter quase etnográfico dos trabalhos produzidos por Devore, Goodall ou Waal na década de 1960, que não passariam despercebidos a nenhum antropólogo, e com Durham não foi diferente. Discussões sobre a validade e o caráter da adoção de abordagem etnográfica na prática da etologia e da primatologia podem ser encontradas em Lestel (2004), McGrew (1996) e Rapchan (2004; 2005), com base em perspectivas distintas. Contudo, o eixo da questão reside tanto na necessidade de propor tratamentos adequados para a abordagem de comportamentos complexos quanto na forte interação entre humano e animal em muitos contextos de pesquisa.

Por sua vez, as referências de Durham (2003) aos registros de Goodall estão sempre acompanhadas de adjetivos e não poderiam ser mais indicativas de aprovação: "descrição vívida" (p. 109), "cuidadosas observaçôes" (p. 115), "descrição cuidadosa” (p. 121), "ampla documentação" (p. 130) ou "descrições sensíveis e detalhadas" (p. 134). É a reflexão dirigida a esse tipo de trabalho sobre comportamento de chimpanzés que predomina no artigo de Durham.

Contudo, os trabalhos que expressam a aproximação entre primatologia, sociobiologia e ecologia comportamental evolutiva são os que têm dominado o cenário dos estudos de comportamento desde os anos 1970 (Rodman, 1999, p. 314). Sua adoção significou tanto o abandono desse caráter "etnográfico" das narrativas quanto a substituição da linguagem natural por uma linguagem mais conceitual para a descrição do comportamento dos chimpanzés. Nenhuma dessas abordagens tem sido objeto de diálogos fluentes com a antropologia sociocultural no geral, mas especialmente no Brasil, onde a biofobia impera entre os cientistas sociais. O texto de Durham, ao ignorar essa bibliografia, é uma expressão dessa postura. 
De fato, como bem sinalizou Kuper (1994, p. 11), há inúmeros debates atuais nas biociências que são profundamente incômodos para as ciências sociais, especialmente para a antropologia, e o artigo de Durham não deixa de expressá-los, porém de forma muito tímida. E equacionálos não se restringe a legar o problema à psicanálise (Durham, 2003, p. 92, 96 e 101), por mais enriquecedor que seja esse olhar.

Uma contribuição efetiva por parte da antropologia sociocultural nesse terreno implica produzir reflexóes que efetivamente avaliem as interfaces entre biociências e comportamento humano, considerando o conhecimento acumulado pelo exercício antropológico (Tuttle, 2001), quando se trata de discutir questóes como cultura animal ou interaçôes humano-animais que resultam na produção de significados, antropomorfização e construção simbólica da cultura, mas também refletindo com rigor e sem preconceitos sobre os resultados das pesquisas de cunho evolutivo em comportamento animal. Além disso, o caráter do problema força abordagens de aspectos supostamente emocionais dos chimpanzés por perspectivas da antropologia e da psicanálise que só podem ser realizadas de um prisma evolutivo para promover a fundamental distinção entre o que é análogo e o que é homólogo.

$\mathrm{O}$ antigo e rígido dualismo das relações entre inato e adquirido, gene e experiência ou "biológico" e "comportamental" tem sido revisitado, explodindo em várias tendências, inclusive com o abandono da dicotomia (Ingold, 1996; Tomasello, 1999, p. 215-17). A fenogenética construtivista ou a evolução nicho-organismo ecológico (Foladori, 2000, p. 330) é uma das concepçôes mais pertinentes nesse contexto; já a ecologia comportamental evolutiva pauta-se exatamente pela busca de relações entre evolução e comportamento social humano (Winterhalder \& Smith, 1992, p. 3-4).

Recuperar brevemente a história desse debate é importante aqui para demonstrar porque não se pode ignorá-lo nesse contexto crítico. $\mathrm{Na}$ 
Eliane S. Rapchan \& Walter A. Neves. Chimpanzés não amam!

década de 1950, MacArthur produziu a primeira síntese criativa dos elementos da ecologia evolutiva: definição de tópicos centrais (comunidade, diversidade, regulamentação de população, relação entre sexos, estratégias alimentares, equilíbrio competitivo) associada à adoção de premissas darwinistas explícitas, métodos hipotético-dedutivos e modelos matemáticos simples (Winterhalder \& Smith, 1992, p. 11-12). Em 1960, outros pesquisadores passaram a desenvolver trabalhos de campo com primatas e outros animais na busca de respostas evolutivas às condições socioecológicas locais (id., p. 6).

A ecologia comportamental evolutiva humana, por seu turno, surgiu da coletânea Evolutionary biology and human social behavior: an anthropological perspective, editada por Chagnon e Irons em 1970 (Cronk, Chagnon \& Irons, 2000, p. 3), marcada pela proximidade com a etologia e influenciada pelos trabalhos anteriores de William Hamilton, George C. Williams, Robert H. MacArthur, Eric R. Pianka e Robert L. Trivers (id., p. 3-4). Sua preocupação central é abordar nosso comportamento como um fenômeno sobre o qual as forças da seleção natural também atuam (id., p. 4), sobretudo com referência a forrageio, reprodução, demografia e troca de cônjuges, tomando como parâmetro principalmente grupos caçadores-coletores.

Em 1970, a teoria evolutiva chegou até a ser adotada por alguns antropólogos culturais que associaram os temas tradicionais da disciplina a testes de hipóteses para discutir a adaptação no âmbito do comportamento humano (id., p. 5). Contudo, a crítica de Marshall Sahlins a essa abordagem recebeu enorme aceitação na antropologia sociocultural e inaugurou a cisão entre tais campos (id., p. 6-10), reforçando aprioristicamente a recusa da influência da história evolutiva sobre o comportamento humano e a cultura (id., p. 11).

Hoje, a antropologia americana está cindida entre a antropologia cultural, sob as formas do interpretativismo (Geertz, 1978; Rabinow \& 
Revista de Antropologia, São Paulo, USP, 2005, v. 48 № 2.

Sullivan, 1979), da hermenêutica (Geertz, 2000; Marcus \& Fischer, 1999) e do pós-modernismo (Marcus \& Myers, 1995; Sangren, 1988), e a antropologia científica, com pesquisa orientada para a análise evolucionista do comportamento humano, influenciada pela psicologia evolutiva (Tooby \& Cosmides, 1992), co-evolução (Boyd \& Richerson, 1995; Durham, 1991), ecologia comportamental e teoria da herança dual, cada uma com características próprias (Alvard, 2003, p. 137-39; Smith, 2000, p. 27-33).

Alvard (2003) e Betzig (1997) expressam opções radicalmente distintas, ilustram o jogo de forças no campo e interessam particularmente porque seu debate gira em torno do problema da cultura. Alvard é um antropólogo sociocultural e dirige-se à cultura como um importante fator evolutivo e adaptativo, valorizando a variabilidade e assumindo que ela não pode ser linearmente atribuída à ecologia ou à genética (Alvard, 2003, p. 136-39), refinando os diferentes aspectos da transmissão da experiência pela análise da imitação, do aprendizado observacional e do desenvolvimento mediados por fatores locais (local enhancement) (ibid.). Betzig, por sua vez, enfatiza padrões universais de comportamento quanto a critérios de beleza e aspectos comuns encontrados na maternidade, na paternidade, no parentesco, na sexualidade e nas alianças humanas (Betzig, 1997, p. 2-11), reduzindo ao mínimo, ou mesmo desprezando, o papel da cultura para discutir tais universais.

Por isso, diante desse quadro respeitável, quando Durham opta por não lidar com a legitimidade de abordagens nascidas do neodarwinismo na produção de reflexôes sobre as relaçôes entre biológico e cultural para oferecer uma reflexão antropológica sobre "sentimentos" de chimpanzés, torna evidente que não está disposta a "quebrar ovos para fazer seu omelete". Não basta afirmar que é possível elaborar uma reflexão com base em "laços genéticos e semelhanças comportamentais" (Durham, 2003, p. 91). É preciso que a antropologia sociocultural faça isso sem 
Eliane S. Rapchan \& Walter A. Neves. Chimpanzés não amam!

prejuízo ao conhecimento que já produziu e, ao mesmo tempo, enfrente o debate.

A posição de Durham (2003) diante do problema das comparaçōes interespécies (Pavelka, 2002) também merece destaque. A autora afirma, constantemente, a recusa em extrapolar padróes comportamentais de uma espécie a outra como um procedimento válido (Durham, 2003, p. 112-14), o que supostamente permitiria o escape do diálogo com as biociências. Entretanto, ela própria constrói sua narrativa utilizando dados sobre o comportamento de gorilas e de outros primatas (id., p. 108, 114 e 121) para se referir ao comportamento de chimpanzés. E não deixa de ser irônico que esse tipo de procedimento seja uma prática orientada para as idéias darwinistas aplicadas à primatologia (Pavelka, 2002), que opera com a possibilidade de realização de comparações de comportamentos interespécies, humanos incluídos, além de ser mais um indicativo da desconsideração da autora com o enorme volume de trabalhos recentes sobre chimpanzés influenciados pela sociobiologia.

O exercício comparativo exige fundamentos teóricos. Vale lembrar, por exemplo, que na etnoarqueologia (ver mais referências em <http:// homepages.ucalgary.ca/ ndavid/Homepage/ethnarkybib.pdf>), que discutiu esse procedimento à exaustão, não se fazem analogias diretas, mas se busca evidenciar processos (leis gerais) que podem ajudar a compreender o comportamento humano. Qualquer possibilidade de tanger processos similares em espécies distintas passa necessariamente por uma aplicação acurada da teoria evolutiva.

Há, ainda, uma observação geral a fazer referente a um aspecto central do artigo. Durham (2003, p. 137-39) define as próprias categorias para identificar o que entende por "amor", "ciúme", "amizade" e as considera legítimas para uma reflexão comparativa entre chimpanzés e humanos. Tais "sentimentos amorosos", eixo de reflexão e análise de 
Revista de Antropologia, São Paulo, USP, 2005, v. 48 no 2.

Durham, são, desse modo, definidos pela autora com base no que se pode chamar de senso comum.

Contudo, o artigo não trata da distinção dos, pelo menos, três planos em que os "sentimentos" manifestam-se como fenômenos no plano de pesquisas em primatologia: as emoções manifestas pelos pesquisadores em relação aos primatas (Fouts, 1998; Goodall, 2000; Jahme, 2001), as reações observadas nos grandes símios em suas interaçóes com os humanos, particularmente nas pesquisas que envolvem cognição e ensino de linguagem (Fouts, 1998; Lestel, 2004; Savage-Rumbaugh, Fields \& Tagliatela, 2001; Tomasello, 1999) e os comportamentos registrados nas interações intra-espécies. Estes últimos podem estar associados a reaçôes emocionais e são avaliados pelos pesquisadores do comportamento de chimpanzés por meio de, por exemplo, relações entre diferenças sexuais, dominância e personalidade (Buirski, Plutchik \& Kellerman, 1978), vínculos entre lateralidade nas expressões faciais e expressão de emoções (Lyddy, 2002) ou evidências cutâneas da expressão de emoções (Leavens, Aureli \& Hopkins, 2004).

Pode-se perguntar por que Durham não usa, por exemplo, categorias como "aliança", "resolução de conflito", "inteligência maquiavélica", correntes na etologia e na primatologia, para tratar dos vínculos e dos conflitos entre grupos de filiação e interesse, preferindo explicar o modelo fusão-fissão dos grupos de chimpanzés por meio de expressões como "preferências afetivas" e "parentesco" (Durham, 2003, p. 103).

Ao mesmo tempo, o texto reduz a importância de idéias centrais nesse campo, como é o caso do "altruísmo recíproco" (id., p. 35 e 138), sem manifestar qualquer intenção de reflexão apurada sobre essa importante categoria analítica na ecologia comportamental evolutiva, que consagrou esse "termo" por meio de Robert L.Trivers. Numa contradição aparente, Durham (id., p. 93-94) defende ao mesmo tempo os desdobramen- 
Eliane S. Rapchan \& Walter A. Neves. Chimpanzés não amam!

tos da sociobiologia produzidos por Richard Dawkins, criticando interpretações mecanicistas sobre o trabalho dele, o que teria solapado a riqueza de suas concepções, sem apontar os problemas graves que antropólogos como Kuper (2000) e Sperber (2000) têm identificado na noção de "memes" de Dawkins e na "memerização" da noção de cultura.

Segundo Durham (2003, p. 94-95), a não penetração da psicologia e do evolucionismo biológico nas ciências sociais poderia ser compensada por um diálogo com a neurobiologia, por meio de trabalhos como os de David Goleman e Antônio Damásio. Entretanto, a opção de Durham pelos "sentimentos" como a melhor ponte entre comportamento de chimpanzés e comportamento humano torna-se frágil se observada pela ótica de Damásio, porque esse autor é categórico ao indicar profundas diferenças entre humanos e outros seres nos aspectos relacionados às emoções, aos sentimentos e à consciência.

Para Damásio, as emoções humanas são processos determinados biologicamente e dependem de mecanismos cerebrais estabelecidos de modo inato, anatômica e fisiologicamente, apesar de o aprendizado e a cultura alterarem as expressões dessas emoçôes e lhe conferirem significados próprios (Damásio, 2000, p. 75). Segundo o autor, as emoções humanas são singulares com relação às de qualquer outro ser vivo devido a seus vínculos com juízos, valores e princípios abstratos complexos (id., p. 55). Para pontuar claramente como observa tais distinções, Damásio afirma: "imagino que algumas criaturas não humanas que exibem emoções, mas que provavelmente não têm o tipo de consciência que possuímos, podem muito bem formar as representações que denominamos sentimentos sem saber que fazem isso" (id., p. 57).

Além disso, a mediação entre reações emocionais e sentimentos está intimamente relacionada à consciência. Há diferentes tipos de consciência num ser vivo. Restringindo a análise a apenas duas categorias, aquela referente às necessidades básicas de sobrevivência e reprodução 
(alimento, abrigo, encontro de parceiros sexuais, identificação de perigo ou risco, entre outros) e a associada à percepção de si e dos outros com os quais se relaciona (mãe e irmãos, grupos familiares extensos, dominantes e iguais, grupo social e espécie), tem-se um universo analítico comum a muitos seres vivos.

No caso dos humanos, a consciência sobre si e sobre o grupo pode estender-se por vários planos, extremamente nuançados, a maioria deles definidos por recortes absolutamente simbólicos e abstratos de "pertencimento", ou seja, por recortes que pelo menos aparentemente não se baseiam exclusivamente em lógicas lineares de sobrevivência e reprodução: a família, a aldeia, o clā, as amizades formais, a classe, o gênero, a etnia, a região, a religião, a pátria, a língua, a humanidade.

Ades (1997) trata do problema da consciência animal avaliando as dificuldades metodológicas para enfrentá-la e as implicações relacionadas ao tratamento desse tipo de fenômeno. Segundo o autor, os procedimentos adotados para a abordagem da consciência animal expressam-se por meio de três dimensões: as traduções perceptuais, as analogias antropomórficas e o uso de critérios comportamentais (id., p. 129).

Ades (id., p. 133-34) defende a existência de dois tipos de consciência - uma delas tipicamente humana. $\mathrm{O}$ acesso à consciência animal implica, por sua vez, o enfrentamento dos enormes problemas de tradução perceptual existentes entre os seres humanos e as outras espécies (id., p. 135-37) que incluem, por exemplo, as profundas diferenças entre os recursos de comunicação disponíveis. Por essas razões, segundo ele, se há possibilidade de se produzir conhecimento sobre outra espécie, esse será, necessariamente, produto de uma construção (id., p. 133).

Dito de outra forma, o pesquisador "humaniza", racional ou subjetivamente, os animais que estuda, seja por estratégia de acesso, por buscar similaridades baseadas em comparações ou, simplesmente, porque todos os sistemas de classificação que é capaz de produzir são produtos de 
Eliane S. Rapchan \& Walter A. Neves. Chimpanzés não amam!

um tipo de pensamento que caracteriza e adjetiva os elementos dos conjuntos com base em observações e atribuições de associações derivadas de conteúdos simbólicos.

A existência de "vida psíquica" entre chimpanzés afirmada por Durham (2003, p. 97) padece exatamente desse problema. A autora sinaliza a existência de categorias homólogas (que repartem, portanto, a mesma ontologia evolutiva) entre o desenvolvimento psíquico de chimpanzés e de humanos (id., p. 126) sem considerar a antropomorfização e os limites simbólicos agregados às possibilidades de se avaliar tal fenômeno de modo conveniente.

Volta-se, assim, à pergunta apresentada no início deste artigo. $\mathrm{Ou}$ seja, a produção de conhecimento sobre o comportamento de chimpanzés, mediada que é por fatores associados à subjetividade do pesquisador, afeta o saber produzido ou revela algumas de suas facetas?

Considerando a possibilidade de comunicação não verbal entre humanos e chimpanzés, quanto há de subjetividade na interpretação dos pesquisadores nesses casos (Jahme, 2001)? O que realmente expressam os experimentos com chimpanzés que implicam aprendizado de linguagens para comunicação, dada a intensa intimidade e a forte interação que tal situação promove entre o pesquisador e o pesquisado (Lestel, 2004)?

Essas questōes remetem ao sempre recorrente problema da produção de sentidos. Ou seja, acaso seja possível que os chimpanzés possuam "sentimentos" que possam de algum modo ser mediados por alguma das facetas de suas consciências, esse produto precisaria ainda adquirir sentidos e ser expresso por meio deles para que seja comensurável aos sentimentos humanos.

Em síntese, considerando todas essas implicações do problema, não é possível equivaler ou mesmo comparar os sentimentos humanos com os dos chimpanzés devido à ausência de um elemento explicativo central, aliás muito caro à antropologia sociocultural, que é o fato de o Homo 
Revista de Antropologia, São Paulo, USP, 2005, v. 48 No 2.

sapiens produzir significados em tal grau de complexidade e profusão a ponto de contaminar, por meio de seu exercício de produção simbólica, tudo aquilo que venha a ser integrado a seu universo de pensamento, inclusive os chimpanzés.

Desse modo, e considerando a inexistência até o momento de qualquer pesquisa que tenha elicitado em chimpanzés qualquer grau de produção simbólica, não se pode descartar a recorrência dessa atitude incorrigivelmente humana, particularmente em situações de empatia profunda e contato intenso de pesquisa, inclusive quando se trata do pesquisador registrando a contrapartida "afetiva" do animal com o qual se relaciona intensamente. $\mathrm{O}$ fato de pesquisadores como Damásio enfatizarem a dimensão anatômico-fisiológica do sentimento não autoriza, com base na semelhança genética entre ambas as espécies (entre 95\% e 98\%), o estabelecimento de comparaçôes lineares entre os sentimentos de chimpanzés e de humanos. A ontologia é muito distinta.

Segundo Damásio (2000, p. 350-53), se é possível aceitar a emergência da consciência como um avanço biológico significativo, por outro lado, a extensão da consciência possibilitada pela memória e pelo registro autobiográfico, pelo registro dos fatos e pela memória operacional está diretamente associada ao desenvolvimento do neocórtex em humanos. Por isso a consciência é tão importante para Damásio na discussão sobre os sentimentos: as emoções só podem ser conhecidas pelo indivíduo por meio da consciência. Ou seja, não basta existirem as reações articuladas que constituem a emoção, é preciso haver um self para que a emoção seja percebida como parte de algo em nosso organismo, em nosso ser (id., p. 353).

Desse modo, considerando os rumos tomados até o momento, a melhor estratégia para estabelecer comparações entre humanos e chimpanzés, no que se refere aos sentimentos, é a utilização dos dados acumulados relativos ao comportamento. Há muito o que descobrir e dis- 
cutir a partir dos registros de condutas e interaçôes entre grandes símios, que os primatólogos têm equacionado por meio da adoção de noções como "cultura", "poder maquiavélico", "tradição", "transmissão" e "variabilidade", que podem iluminar o ainda pouco conhecido território das emoções e dos sentimentos no que se refere a semelhanças possíveis entre espécies. Aí, talvez, seja possível encontrar reações, padróes e expressões individuais e coletivas através dos quais seja possível refletir sobre as emoções. Infelizmente, tais aspectos da pesquisa comportamental em primatologia sequer foram mencionados por Durham.

\section{O que está aquém do debate bibliográfico recente?}

A iniciativa de Durham (2003) em tocar em assuntos relativos a aspectos do comportamento humano que apontam para direçóes que não se restringem às explicaçôes do que é apreendido por meio da cultura expressa uma situação crítica e solicita uma tomada de posição mais clara do que a manifesta no artigo em pauta. E isso por uma razão muito simples: desde a crítica da antropologia sociocultural ao evolucionismo cultural e ao spencerismo social (Stocking, 1982), erroneamente batizado de darwinismo social, que resultou no descarte radical por parte dos antropólogos de todo e qualquer paradigma vindo da biologia, predominam nas ciências sociais as explicações que tomam os fenômenos socioculturais como completamente independentes da condição humana, como espécie ou como expressão da natureza humana.

A cultura, por essa perspectiva, teria substituído integralmente as leis da evolução e produzido uma espécie completamente autônoma com relação a elas. Como conseqüência, teria "libertado" os humanos das determinações biológicas, tornando-os seres exclusivamente culturais. 
Revista de Antropologia, São Paulo, USP, 2005, v. 48 № 2.

Tábulas rasas sobre as quais a cultura se deposita por meio da socialização para, então, ganhar vida no sujeito e reproduzir-se no grupo.

O problema dessa assertiva é que muito do que se convencionou identificar como domínio exclusivamente humano tem sido registrado também entre os grandes símios: produção de ferramentas (Goodall, 2000; 1991; McGrew, 1996; Sugiyama, 1997), variação comportamental de grupo para grupo (Wrangham et al., 2001), centralidade da socialização e a importância da sociabilidade na elaboração do comportamento (Dunbar, 1997), comunicação (Parker \& Gibson, 1994; Rumbaugh, Savage-Rumbaugh \& Sevcik, 2001; Tomasello, 1994), tradições (Fragaszy, 2003), cognição (Hauser, 2005; Tomasello, 1999) e cultura (Tomasello, 1999; Whiten et al., 1999; Wrangham et al., 2001).

Por outro lado, e ao mesmo tempo, estudiosos da mente (Mithen, 2002) e do cérebro (Damásio, 2000) humanos têm identificado aspectos evolutivos e anatômico-fisiológicos que apontam para diferenças e semelhanças entre humanos e grandes símios e para o modo como tais diferenças associam-se à capacidade de produzir abstrações, como símbolos e consciência. Em ambos os casos, referem-se ao humano como produto de um processo evolutivo cuja singularidade está, também, relacionada à sua condição de espécie, ao potencial que a mente possui para desenvolver, apreender e reproduzir cultura, à centralidade da vida social e ao corpo biológico como suporte ativo de tudo isso.

Assim não é suficiente fazer referências à teoria do gene egoísta de Richard Dawkins, à neurobiologia de Antônio Damásio, à psicologia evolutiva de Robert L.Trivers ou aos registros de comportamento de chimpanzés feitos por Jane Goodall ou Franz de Waal para estabelecer diálogo consistente entre as ciências sociais e as biociências. É preciso que os antropólogos socioculturais informem-se e tomem posições menos xenófobas com relação ao imenso volume de pesquisas que associam comportamento humano a aspectos biológico-evolutivos. 
Eliane S. Rapchan \& Walter A. Neves. Chimpanzés não amam!

Mesmo adotando atitudes radicalmente críticas que se manifestem por meio de enxurradas de questionamentos e dúvidas, é necessário deixar bem claro até que ponto a antropologia sociocultural está mesmo disposta a discutir os próprios paradigmas. É possível para a antropologia sociocultural levar adiante a afirmação "o homem ainda é um animal, produto da evolução biológica” (Durham, 2003, p. 86-87)? Caso a resposta seja afirmativa, como conduzir a compreensão do humano de uma perspectiva evolucionista sem recair no determinismo?

Pois, se como Durham afirma, "a questão do homem e dos fundamentos biológicos da cultura humana constitui uma preocupação importante da antropologia” (id., 2003, p. 86), então por que a antropologia sociocultural abandonou completamente essa interface e os cursos de graduação e pós-graduação na área omitem tais questões e não estimulam pesquisas nessa direção? Durham (id., p. 97) identifica a inexistência de "trabalho comparativo interdisciplinar sistemático" entre as pesquisas sobre comportamento de chimpanzés e as ciências do homem, mas não aponta as razões para isso. Nem mesmo resvala numa mea culpa.

Dentre as poucas vozes dissonantes, as incômodas posições de LéviStrauss em favor do diálogo da antropologia com as biociências apontam para direções mais favoravelmente radicais (Lévi-Strauss, 1993, p. 26; Massenzio \& Lévi-Strauss, 2001) do que a maioria dos antropólogos socioculturais, e mesmo Durham (2003, p. 86-87), parecem admitir. Além de Lévi-Strauss, pode-se citar Asquith (1995), Ingold (1995; 1996), Kuper (1994; 2000), Sperber (1985; 2000). Quantos mais?

Um forte indício dessa tão destacada dificuldade encontra-se na adoção de critérios de distinção entre homens e animais, legando aos primeiros o domínio da "consciência, [do] raciocínio e [da] linguagem" (Durham, 2003, p. 87), sem enfrentar criteriosamente a produção recente relativa às pesquisas sobre chimpanzés do viés do que tem sido 
Revista de Antropologia, São Paulo, USP, 2005, v. 48 no 2.

chamado de "cultura material" (McGrew, 1996), "cultura de chimpanzés” (Böesch \& Tomasello, 1998; Wrangham et al., 2001; Whiten et al., 1999), "cognição" (Böesch, 1991; De Waal, 2001a; Joulian, 1996; Tomasello, 1999; Tomasello \& Call, 1997), "entendimento" (Hoof, 2001), "percepção" (Cheney \& Seyfarth, 1990), "vida social” (Baker \& Smuts, 2001; Dunbar, 1997; Sapolsky, 2004; Wilson \& Wrangham, 2003), "capacidade de dissimulação e comunicação" (De Waal, 2000), "resolução de conflitos" (Arnold \& Whiten, 2001; Baker \& Aureli, 2001; Baker et al., 2000; Boehm, 2001; Mason \& Mendoza, 1993), entre outros.

Cada um desses aspectos, se não se configura rigorosamente como "consciência, raciocínio e linguagem" tal como encontrados no domínio humano, merece, contudo, avaliação quanto a seus limites e alcances, para que se possa efetivamente definir diferenças e semelhanças, fronteiras, gradações e distinções entre "parentes" tão próximos. Pois, se como afirma Durham (2003, p. 98), não é possível tratar "a comunicação em geral, a cooperação grupal e a fabricação de instrumentos, as análises sobre a inteligência" no espaço restrito de um artigo, a opção pelo enfoque exclusivo nos "sentimentos", que desconsidera suas interfaces com as outras dimensões do comportamento, repete um procedimento tido como equivocado pela antropologia do final do século XIX, apontado por Boas e Malinowski e que pode ser também um fator limitante para a primatologia contemporânea. A saber, o isolamento das variáveis do comportamento no âmbito da coleta de dados e de análise, ao invés de considerá-las por uma perspectiva que leve em conta, ainda que parcialmente, a idéia de totalidade ou, ao menos, de interconexão entre fenômenos (Rapchan, 2004).

Exemplo disso é quando a autora associa o estudo das emoções em Lévy-Bhrull e Malinowski às possibilidades comparativas entre o comportamento humano e o do chimpanzé, mas os vínculos entre os dois campos 
Eliane S. Rapchan \& Walter A. Neves. Chimpanzés não amam!

não são explorados ou sequer explicitados. $\mathrm{O}$ único ponto em comum mencionado pela autora são as "necessidades básicas" (Durham, 2003, p. 87-88), porém não há clareza sobre o que isso significa. Seriam necessidades materiais imediatas, necessidades de fundo evolutivo ou outras?

De fato, é preciso ir além e encaminhar reflexões efetivas sobre as relações entre "razão" e "emoção", "cultura” e "herança”, "cognição" e "relações sociais" com base na adoção de procedimentos comparativos para os dados sobre comportamentos humanos e de grandes símios, considerando o arcabouço teórico-conceitual da antropologia social, da etnoarqueologia, da etologia, da neurobiologia, da primatologia, da psicologia evolutiva e de outras disciplinas.

Por fim, um aspecto não menos importante: o problema das relações sociais entre chimpanzés. Durham, como é concebível para qualquer antropólogo sociocultural, tem dificuldades em lidar com a idéia de que chimpanzés produzam cultura ou estabeleçam relações sociais. Assim, diante da insistência dos primatólogos em afirmar a existência de tais fenômenos, resta àqueles cientistas sociais que decidem dialogar com tais pesquisas enfrentar essas noções, revendo as próprias referências e analisando cuidadosamente os usos e os sentidos de expressões que têm aparecido com enorme freqüência na literatura da primatologia e cujos nomes são idênticos àqueles correntemente utilizados para o tratamento de fenômenos humanos.

Durham dá o primeiro passo ao colocar em evidência as várias referências sobre a vida coletiva dos chimpanzés. Enfatiza aspectos do comportamento e os relaciona à experiência social e às emoções em mamíferos superiores (Durham, 2003, p. 95). Destaca, dentre eles, no plano da composição do grupo, a dominância da reafirmação e contestação de posições hierárquicas na vida social dos chimpanzés (id., p. 103) e a importância da consangüinidade em sua vida social (id., p. 133). No que se refere à sexualidade, a autora menciona a promiscuidade 
Revista de Antropologia, São Paulo, USP, 2005, v. 48 no 2.

sexual como um dado importante de seu comportamento social (id., p. 106-7), os fortes vínculos existentes entre instinto sexual e experiência social para humanos e chimpanzés (id., p. 111), a sexualidade e as relações de dominação como elementos fundamentais para a vida social dos chimpanzés (id., p. 117). Por fim, Durham enuncia a base genética do comportamento social (id., p. 135-36) e os fortes vínculos entre comportamento social e desenvolvimento de inteligência (id., p. 135).

Espantoso é que, depois de tudo isso, a autora descarte a legitimidade do uso da expressão "social" para se referir ao comportamento de chimpanzés afirmando, simplesmente, que, "utilizando de forma metafórica conceitos que se aplicam mais apropriadamente a seres humanos, diríamos que esse monopólio [de fêmeas por um único macho dominante] impede a existência de 'sociedades' e restringe o grupo a 'famílias"' (id., p. 105). Não é satisfatório reduzir tudo a metáforas. Por que desprezar dados sobre estratégias reprodutivas de fêmeas em várias posições hierárquicas e de machos de status mais baixo (Hrdy, 2001; Goodall, 1986) que demonstram que, entre chimpanzés, o macho dominante não é o único a reproduzir-se e que, além disso, as fêmeas de um grupo podem copular secretamente com machos de outros grupos? Esse material reforça os indícios a favor de uma maior complexidade no funcionamento e na organização dos grupos de chimpanzés.

Tomasello (1999, p. 16-17) apresenta um levantamento das características sociais comuns a todos os mamíferos identificadas em pesquisa: reconhecimento da individualidade dos membros do grupo; relaçôes diretas baseadas em parentesco, amizade e dominação; previsão do comportamento individual com base em estados emocionais e direção de locomoção; uso de muitos tipos de estratégias sociais e comunicativas para ampliar o acesso a recursos valiosos; cooperação na solução de problemas e na formação de coalizões e alianças; e participação em várias formas de aprendizado social. 
Eliane S. Rapchan \& Walter A. Neves. Chimpanzés não amam!

Tais fatores apontam para a existência de agrupamentos não baseados exclusivamente em laços familiares, ao contrário do que afirma Durham. Quais argumentos a antropologia sociocultural pode apresentar para contrapor ou analisar as evidências acima com o intuito de negar a existência de dinâmicas grupais entre mamíferos e ratificar a singularidade humana nesse plano?

Estaria Durham (2003) defendendo a existência de "famílias", ao invés de "sociedades", num esforço em defender o tabu do incesto como fundador da sociedade humana, mediador das relaçôes entre natureza e cultura (Lévi-Strauss, 1982)? Se é isso, por que, então, ela própria apresenta dados que reforçam a quase total ausência de registros de incesto entre fêmeas chimpanzé e seus filhotes (Durham, 2003, p. 115-16)?

A organização coletiva dos chimpanzés não é, definitivamente, exclusivamente "familiar", uma vez que eles são capazes de reconhecer e estabelecer diferentes associações baseadas em vínculos familiares e alianças, bem como relações de hierarquia e afinidade, e também fazem uso de vários tipos de estratégias sociais e comunicativas para ampliar os acessos do grupo a mais recursos. Podem cooperar com os da mesma espécie, mesmo que não consangüíneos, para resolver problemas e, na formação de coalizões e alianças, envolvem-se em várias formas de aprendizado social, além de serem capazes de compreender a dinâmica de relações nas quais não estão diretamente envolvidos (Tomasello, 1999, p. 16-17)!

Toshisada Nishida foi o primeiro a propor um modelo social para os grupos de chimpanzés: a "unidade-grupo" ("unit-group”) que os primatólogos ocidentais rebatizaram de "comunidade" ("community") (Stanford, 1998, p. 400). Segundo esse modelo, o grupo possui uma estrutura abrangente, da qual fazem parte, indiferenciadamente, todos os membros que a ele pertencem. Posteriormente, Goodall identificou três tipos de vínculos fortes. Dos mais estáveis e duráveis aos mais fra- 
cos: as unidades fêmea-filhotes, que se prolongam até a vida adulta, seguidas pelas relações entre fêmeas aliadas (parentes ou não), que podem inclusive atuar como alomães - apesar de isso ser raro entre chimpanzés (Hrdy, 2001) -, e as alianças entre machos (irmãos ou não) (Goodall, 1991, p. 203-5).

Em síntese, quando se trata de comparar comportamentos entre grandes símios e humanos, não é suficiente observar os comportamentos, mas também considerar suas ontologias, isto é, o que as estimula e o que as reprime. É por essa via, talvez, que o clássico debate sobre as relações entre natureza e cultura, que recebeu tantas contribuiçôes de Lévi-Strauss, deva ser retomado, inclusive pela perspectiva da fluidez de tais fronteiras.

\section{Além do debate bibliográfico recente}

Há, ainda, no texto de Durham (2003) uma série de conclusões que estão além dos limites definidos pelo material coletado e analisado pelos pesquisadores dedicados ao comportamento de chimpanzés. A primeira, central e óbvia, implica a afirmação de que tais animais têm "sentimentos amorosos" comensuráveis aos humanos (id., p. 91).

Ora, os fenômenos associados aos sentimentos no âmbito humano catalisam vários planos. A unidade (pessoa, sujeito, ator, indivíduo, ser) que é singular possui personalidade própria, vida mental, psíquica e sensível que, ao mesmo tempo, só existe enquanto tal por ter sido forjada no interior de um coletivo (cultura, sociedade), com o qual interage constantemente por inúmeras vias intersubjetivas e que reproduz valores e sentidos grupais com base em dinâmicas próprias.

Tomasello (1999, p. 52-53 e 80-81) associa a todos os mamíferos a capacidade de reconhecimento do grupo e apenas aos primatas a capa- 
Eliane S. Rapchan \& Walter A. Neves. Chimpanzés não amam!

cidade de identificar relações nas quais não participam diretamente. Mas só os humanos são capazes de produzir historicamente artefatos culturais, cuja reprodução é diretamente dependente da capacidade de internalização e inovação das práticas sociais pelos filhos. Por isso, segundo o autor, os humanos possuem uma característica única: a capacidade de se identificar com outros seres humanos (Tomasello, 1999, p. 90-91).

Os sentimentos humanos não estão, pois, desassociados das interações intersubjetivas constantes entre o sujeito e seus pares. É verdade que alguns pesquisadores têm registrado trajetórias particulares de animais, algo como suas "histórias de vida" (Goodall, 1991; Savage-Rumbaugh \& Lewin, 1994), e outros tipos de observação pautada nos indivíduos que apontam para a existência de comportamentos singulares diante do grupo e da espécie (Tomasello, 1999, p. 6). Segundo Lestel (2004, p. 70-73), e isso se acentua em animais que estabelecem relações intensas e constantes com humanos.

Da mesma forma, os estudos sobre populações de chimpanzés têm identificado grande variabilidade nas características comportamentais coletivas de um grupo quando comparado a outros (Wrangham et al., 2001). Do mesmo modo, o "lugar" ocupado pelo indivíduo no interior do coletivo, quanto ao sexo, à idade e ao status, produz dinâmicas de interação próprias (Buirski, Plutchik \& Kellerman, 1978; Fouts, 1998; Hrdy, 2001; Goodall, 2000; 1991).

No entanto, há um fator último a considerar nesse plano e que diz respeito à produção cultural. Como mencionado anteriormente, não existem indícios convincentes de que chimpanzés produzam dinâmicas simbólicas comparáveis às das culturas humanas (Mithen, 2002), o que impede qualquer pressuposição de que eles elaborem suas reações emocionais de modo idêntico aos humanos, apesar de Tomasello (1999, p. 18-19) defender que chimpanzés têm compreensão de eventos físicos e sociais complexos mas não vêem o mundo por meio de estados men- 
Revista de Antropologia, São Paulo, USP, 2005, v. 48 № 2.

tais causais e intencionais - no plano das emoções, chimpanzés e humanos são distintos.

Grandes símios podem inferir o que vai acontecer quando vêem outro de sua espécie movendo-se em direção à comida e podem até mesmo usar inteligência e estratégias sociais para afetar os rumos dos eventos. Contudo, só os humanos são capazes de ser afetados no comportamento, nas intenções ou nos estados mentais (Tomasello, 1999, p. 21) por uma ação dirigida para a obtenção de comida por parte de um semelhante. Isso ocorre devido ao que os psicólogos chamam "teoria da mente", ou seja, a capacidade humana de pensar, cogitar ou imaginar o que se passa pela mente de outro ser humano e que se desenvolve a partir dos 14 meses de idade (id.).

Daí emerge um importante fundamento simbólico relacionado às atividades sociais humanas preexistentes e cuja causa pode estar principalmente associada ao aprendizado dos símbolos lingüísticos, mas também a outros artefatos simbólicos (id., p. 95-96). Isso porque o processo de aquisição e uso dos símbolos da fala nos processos sociais transforma de modo único nossa capacidade cognitiva e simbólica.

A expansão das capacidades cognitivas e simbólicas humanas proporcionou uma explosão simbólica diretamente relacionada à perpetuação, reprodução e transmissão das culturas (id., p. 125-26 e 164). Tudo isso, evidentemente, molda os sentimentos humanos nos contextos culturais próprios, mesmo que as emoções possuam um fundamento evolutivo comum.

As emoções podem relacionar-se à dor, à ausência, ao perigo, ao prazer, à satisfação e à curiosidade e estão intimamente associadas às capacidades de percepção e reação de um ser, humano ou não. Nesse plano, os registros sobre as reações dos chimpanzés diante de estímulos diversos são fontes riquíssimas (Ladygina-Kohts, 2002; Leavens, Aureli \& Hopkins, 2004; Wrangham \& Peterson, 1998). 
Contudo, a elaboração dessas reações e as vias pelas quais esses estados de bem e mal-estar se manifestam dependem dos diferentes graus de percepção e expressão associados a cada reação e à possibilidade de comunicá-los. Por isso, é inadequada a suposição de Durham de que o fato de as emoções não emergirem da consciência seja suficiente para que elas sejam mecanicamente associadas a "padrões geneticamente transmitidos" (Durham, 2003, p. 92). Tal linearidade de raciocínio não encontra o mais mínimo sustento na literatura especializada, pois desconsidera entre outras coisas a importância da experiência coletiva nesse processo.

É importante, também, tratar aqui de um sentimento para o qual Durham dedicou especial atenção que é o amor. Segundo a autora, o amor seria um comportamento emocional que permitiria a comparação entre humanos e chimpanzés (id., p. 98). O problema dessa perspectiva é aceitar uma universalidade do sentimento "amor" (ibid.) como algo desprovido de sentidos socioculturais e históricos, ao menos quando se pensa em "amor humano", num sentido genérico, com base em uma definição pautada no senso comum (id., p. 99).

Durham parte de um significado específico para o amor proveniente, segundo ela, da tradição judaico-cristã para verificar se ele é aplicável à vida emocional dos chimpanzés (id., p. 99)! Teorias tradicionais religiosas judaico-cristãs mais senso comum não podem orientar qualquer análise dos "sentimentos" dos chimpanzés, amorosos ou não, a não ser que se considere que isso orienta o sentido héctico de um certo conjunto de pesquisadores e que seja este o objeto da análise: o modo como os primatólogos ocidentais atribuem sentido às relações afetivas que eles estabelecem com os chimpanzés ou às relações entre chimpanzés observadas com base em pesquisas sobre comportamento. 
Ao fim, vale reproduzir aqui algumas idéias de Tomasello sobre os riscos e problemas da romantização ou antropomorfização das habilidades cognitivas de outras espécies:

I must also say at this point that anthropomorphizing or romanticizing the cognitive abilities of other animal species will not help us to answer these difficult questions. By this I do not mean to imply that researchers should only look for differences between human and nonhuman primate cognition. On the contrary, if we are going to identify what is uniquely human, as well as what is uniquely chimpanzee or uniquely capuchin, it is crucial that scientists look for both similarities and differences. (Tomasello, 1999, p. 206)

Jane Goodall (2000) e outros pesquisadores têm adotado posturas semelhantes à propagada por Tomasello para analisar outros aspectos do comportamento de grandes símios. Defendemos que a mesma atitude deva ser tomada no tratamento de emoções e sentimentos, humanos ou não.

\section{Significado ainda que tardio}

Dentre as coisas sobre a evolução humana que já podemos considerar como claras, a origem da significação na linhagem hominínea é de longe a mais retumbante. $\mathrm{O}$ quadro evolutivo da significação tornou-se bastante cristalino para os que estudam a evolução humana a partir do final da década de 1980 e início da de 1990 (Foley, 1997). Tal quadro revela que a incorporação de um módulo de significação em nossa mente ocorreu de forma abrupta, revolucionária, e não de forma gradativa, lenta e aditiva como sói acontecer na maioria dos processos evolutivos, 
Eliane S. Rapchan \& Walter A. Neves. Chimpanzés não amam!

mesmo em nossa linhagem (Klein, 1999; Klein \& Edgar, 2005; Boyd \& Silk, 2006; Lewin, 2005) ${ }^{1}$.

Hoje em dia é consenso que novidades evolutivas podem aparecer e ser fixadas de forma abrupta pela seleção natural. Desde a defesa contundente do "equilíbrio intermitente", realizada por Sthepen Gould e Niles Eldredge nos anos 1970-1980 (Eldredge \& Gould, 1972; Eldredge et al., 1997; Stearns \& Hoekstra, 2003), os biólogos evolucionistas não se sentem mais desconfortáveis em aceitar eventos evolutivos pontuais, caracterizando o que se denomina hoje de evolução saltatória. Na verdade, faz muito sentido que a fixação de um módulo mental associado à significação tenha ocorrido de forma abrupta e revolucionária, uma vez que é muito difícil imaginar, por exemplo, a emergência de "meia" capacidade de significação. Ou uma capacidade de atribuir significados que perpasse apenas alguns aspectos de nossas vidas.

Outra peculiaridade da origem da propriedade de significação que chama a atenção é que ela ocorreu muito recentemente, provavelmente entre 40 e 45 mil anos, para alguns entre 70 e 80 mil anos (Klein, 1999; Klein \& Edgar, 2005; Boyd \& Silk, 2006; Lewin, 2005; Streinger, 1999). Por isso, é possível afirmar que aquilo que podemos chamar de humanidade existe no planeta, de fato, há muito pouco tempo, considerando que o percurso evolutivo de nossa família, a dos hominíneos, como linhagem independente, remete-se a pelo menos 7 milhões de anos (Foley, 1997; Mithen, 2002).

$\mathrm{O}$ quadro que se configurou nos últimos 15 anos sobre quando e por que a capacidade de significação foi fixada (muito provavelmente pela seleção natural) não poderia destoar mais daquele defendido anteriormente, sobretudo nos anos 1960 e 1970. Até meados dos anos 1970, acreditava-se que nossas características mais nobres e refinadas deviam remeter-se ao início de nossa linhagem evolutiva. Em outras palavras, esperávamos muito dos primeiros hominíneos. Para tornar uma longa 
Revista de Antropologia, São Paulo, USP, 2005, v. 48 no 2.

história a mais compacta possível, basta dizer que a esmagadora maioria dos paleoantropólogos defende hoje a idéia de que, entre 7 e 2 milhôes de anos atrás, nossos ancestrais eram praticamente chimpanzés em pé.

Como já salientado, descobriu-se também que nossos parentes mais próximos (bonobo, chimpanzé, gorila e orangotango) exibem várias características que pensávamos, até meados dos anos 1980, se restringirem ao Homo sapiens (Stanford, 2001; Mitani et al., 2002). Fabricação e uso de ferramentas, comportamentos aprendidos, organização social complexa, formação de alianças não determinadas pela consangüinidade e evitação de incestos são apenas algumas dessas características que hoje sabemos ocorrer ad nauseam nos grandes símios africanos e asiáticos, apenas em graus mais modestos ou veiculadas por estratégias menos elaboradas (Tomasello, 1997; Stanford, 2001; Marks, 2002; Aurelli \& Waal, 2000; Toth et al., 1993).

À medida que se conheceu melhor o registro fóssil hominíneo e a socioecologia dos grandes símios (cf., para uma revisão, Stanford, 2001; Mitani et al., 2002), tornou-se claro para a maioria dos paleoantropólogos que a única característica que, de fato, nos aparta qualitativamente dos grandes símios é a capacidade de significação, que neles não existe nem mesmo embrionariamente (Marks, 2002; Lock, 2000). Nesse sentido, a definição de cultura como produção simbólica (Geertz, 1978) por parte da antropologia sociocultural contemporânea é mais do que apropriada, até mesmo pelo prisma evolutivo.

Nem a bipedia, nem a capacidade de fabricar e utilizar instrumentos de pedra, nem cérebros grandes e, por mais incrível que possa parecer, nem mesmo o surgimento de nossa espécie, o Homo sapiens, garantiram por si só a emergência de uma capacidade de simbolização, ainda que pálida (Foley, 1997).

Nenhum hominíneo antes de 45 mil anos, incluindo aí o Homo sapiens, que surgiu no planeta por volta de 200 mil anos (McDougall et 
Eliane S. Rapchan \& Walter A. Neves. Chimpanzés não amam!

al., 2005), utilizou osso, dente ou chifre como matéria-prima para fazer ferramentas, tampouco imprimiu qualquer tipo de estilo pessoal ou grupal às ferramentas de pedra que fabricou ${ }^{3}$. Nem ao menos enterrou seus mortos sob a vigência de qualquer ritual. Adornos, painéis pintados em paredôes ou quaisquer outros tipos de manifestação simbólica, artística ou estética também nunca foram encontrados anteriormente ao marco cronológico supramencionado.

Tal quadro não poderia ser mais distinto quando contrastado com o acervo atual de comportamentos e atitudes humanas. Como a antropologia moderna ressalta à exaustão, a atribuição de valores simbólicos, abstratos, permeia todas as dimensóes da vida, de modo que ela está sempre suspensa numa teia de significados, para adotar uma das expressões favoritas dos antropólogos de linha interpretativista (Geertz, 1978). Decisões, comportamentos, tempos comuns e rituais estão inquestionavelmente marcados pela atribuição de sentidos dirigida a todas as interaçôes e formulações.

Conforme já mencionado, tal quadro se esboça apenas e tão-somente a partir de 45 mil anos atrás, por meio daquilo que se convencionou denominar, nos últimos 15 anos na literatura especializada, de Revolução Criativa do Paleolítico Superior (RCPS) (Klein, 1999; Klein \& Edgar, 2005; Mellars, 2005; Bar-Yosef, 2002). Os registros arqueológicos dessa revolução abundam na Europa e no Oriente Médio, como se pode ver no trabalho de Straus (2005), razão pela qual as pesquisas sobre essa região serão o foco da análise. Recentes descobertas efetuadas no sul da África podem acabar estendendo esse limiar para 70 ou $80 \mathrm{mil}$ anos (Henshilwood et al., 2002; 2004; Yellen et al., 1995), mas as evidências até agora obtidas a favor de uma data mais antiga para a RCPS ainda precisam passar por um escrutínio mais apurado por parte da comunidade científica. 
O fato é que abruptamente, por volta de 45 mil anos atrás, o perfil do registro arqueológico mudou completamente se comparado com os períodos anteriores (Mellars, 2005; Klein, 1999, Klein \& Edgar, 2005). A caixa de ferramentas de pedra de nossos antepassados, que antes não ultrapassava 20 instrumentos especializados, saltou para cerca de 75; a forma dessas ferramentas, além de atender a necessidades funcionais, passou também a expressar estilos pessoais ou grupais, manifestando identidades individuais ou coletivas (etnicidade); artefatos de osso, chifre e dente começaram a ser usualmente fabricados e utilizados; adornos corporais passaram a ser amplamente usados; os mortos começaram a ser sepultados ritualisticamente; os instrumentos de osso passaram a receber rica decoração; e, mais importante ainda, esculturas e logo depois pinturas parietais passaram a abundar.

Foi apenas concomitantemente ou logo depois da RCPS que os humanos, agora completamente modernos (em anatomia e comportamento), deslocaram-se para além da África (Lahr \& Foley, 1994; Stringer, 1997), ocupando todas as regiôes do planeta, inclusive as mais remotas e frias. No processo, ao que tudo indica, foram substituindo pelo caminho os hominíneos arcaicos ainda presentes no planeta, entre eles os neandertais, que sucumbiram 10 mil anos depois da tomada da Europa pelo homem moderno (Arsuaga, 2005; Boyd \& Silk, 2006; Lewin, 2005; Mellars, 2003).

Além, obviamente, da capacidade de simbolização, a RCPS injetou criatividade ilimitada em todos os setores da vida humana (Klein, 1999; Mellars, 2003). Para alguns, isso reflete a fixação em nossa mente de um novo módulo mental que passou a interagir e a gerenciar os módulos de inteligência especializada. Outros preferem argumentar que o que ocorreu foi apenas a queda das barreiras que mantinham as inteligências especializadas compartimentadas, permitindo grande fluxo de informação entre elas (Mithen, 2002). 
Eliane S. Rapchan \& Walter A. Neves. Chimpanzés não amam!

Dois fatores conspiram desfavoravelmente para uma compreensão anatômica dessa inovação: primeiro que ela não deixou qualquer marca na parte interna dos ossos do crânio e, segundo, que não existe uma relação anatômica rigorosamente definida entre módulos mentais (ou inteligências especializadas) e regiōes cerebrais (Pinker, 1999; 2004; Mithen, 2002; Lock, 2000; Kolb \& Whishaw, 2001). Exemplo disso é que mesmo a velha associação estrita entre a fala e as regiões de Broca e de Wernick no neocórtex, por décadas cantada em prosa e verso, já foi superada. Pesquisas neurobiológicas recentes vêm demonstrando a grande importância que os núcleos basais exercem no controle da fala (Kolb \& Whishaw, 2001).

Em resumo, a capacidade de simbolização é algo muito recente na linhagem hominínea e não caracteriza sequer a totalidade do percurso evolutivo de nossa espécie, o Homo sapiens. Mesmo nela, o fenômeno é bastante recente. Significa dizer que não podemos equivaler Homo sapiens a humanidade, na medida em que a primeira se define pela capacidade de simbolização e que, conforme muito bem expressou Marks (2002), a significação não pode ser vista apenas como uma camada de glacê sobre o bolo, reduzida a uma perspectiva estratigráfica, porque ela também faz parte da massa, está contida no trigo, no leite e nos ovos. Assim, até que se saiba mais sobre a RCPS e suas bases neurobiológicas, teremos de nos contentar com as expressões "homem anatomicamente moderno" e "homem comportamentalmente moderno", ainda que essas expressões não dêem conta de uma nomenclatura biológica formal (Klein, 1999; Mellars, 2003).

O corolário do quadro apresentado acima está obviamente associado ao contexto da discussão tratada neste artigo: se mesmo em nossa linhagem evolutiva a significação é bastante recente, é evidente que não há a mais remota possibilidade evolutiva de a mesma se manifestar em qualquer grau nos grandes símios africanos e asiáticos. Em outras palavras, 
os chimpanzés estão há pelo menos 14 milhões de anos distantes do significado. Sete desses quatorze referem-se ao tempo evolutivo da própria linhagem, quando a mesma se separou do ancestral comum que repartiu com a dos hominíneos o bendito elo perdido. Os outros sete referem-se ao tempo que foi necessário em nossa própria linhagem para que a fixação do módulo de significação ocorresse.

A única alternativa seria admitir que um módulo de significação foi também fixado no cérebro do chimpanzé em algum momento da evolução desses símios, de forma paralela e independente da ocorrida conosco. Isso é mais que improvável, tendo em vista que a evolução biológica é um processo histórico, no qual os passos anteriores limitam de certa forma os possíveis passos futuros sem, no entanto, determinar qual das alternativas possíveis será fixada (Stearns \& Hoekstra, 2003).

A fixação da capacidade de significação só se deu ou só se tornou uma alternativa adaptativa relevante para os humanos, tendo em vista o encadeamento, por puro acaso, de uma série de novidades evolutivas anteriores que a tornaram funcional num momento específico de nossa evolução. Seria impossível que um módulo de significação emergisse e fosse fixado em um cérebro de $400 \mathrm{~cm}^{3}$, por exemplo, porque o mesmo carece de complexidade estrutural para tanto. Assim como a fabricação de instrumentos, pouco ou nada traria de vantagem adaptativa para uma linhagem de grandes primatas quadrúpedes, cujos membros estão todos comprometidos na locomoção.

A existência de hominíneos capazes de resolver problemas concretos complexos, como moldar a pedra em um número significativo de instrumentos especializados, organizar-se para a caça coletiva e articular-se funcionalmente em grandes grupos sem mediação de capacidade simbólica, é algo hoje que escapa à nossa compreensão, pois tais características "nobres" são indissociáveis da capacidade humana de simbolizar. 
Assim, é muito difícil para um humano entender e admitir como seres muito próximos a nós, com grande capacidade de resolução de problemas complexos, por exemplo os neandertais, faziam-no sem se valerem de valores simbólicos. Certamente, nossos ancestrais eram também capazes de expressar estados mentais de prazer, dor, decepção, excitação e muitos outros. Mas, assim como os chimpanzés, a expressão desses estados também não passava por qualquer tipo de valoração abstrata (Tomasello, 1999).

Em suma, quando o registro paleontológico e arqueológico de nossa evolução é avaliado criticamente, fica claro que não são apenas os chimpanzés que são capazes de esboçar expressões muito próximas às humanas, sem contudo "contaminá-las" com sentidos abstratos. Na realidade, essa parece ter sido a regra em nossa própria trajetória evolutiva (Klein, 1999; Mellars, 2003).

\section{Comentários finais}

Emoções e sentimentos não são, de fato, um tema privilegiado em antropologia. Apesar de estarem implicitamente presentes na investigação antropológica, na grande maioria dos casos, o problema não é submetido a profundos escrutínios. Sendo assim, as motivaçōes de Durham (2003) para tratar das emoçôes dos chimpanzés, em que pese a importância atual do tema, perderam a força da iniciativa por duas importantes razóes.

De um lado, por ter deixado de enfatizar (e enfrentar) pontos críticos de troca e diálogo que precisam necessariamente existir entre a biologia evolutiva e as ciências sociais no cenário que se configura atualmente. Quais são as contribuições efetivas que as ciências sociais podem trazer para a discussão e em quais temas e contextos uma análise proveniente da antropologia sociocultural faria realmente diferença? 
De outro lado, a possibilidade de unificar os estudos sobre grandes símios e refletir sobre suas relações com os seres humanos passa, por definição, pela utilização de teoria evolutiva de ponta. Não há justificativa possível para comparações sem considerar tais princípios. Sem aceitar essa assertiva, as discussões de antropólogos, biólogos e cognitivistas, etólogos, filósofos, neurobiólogos, primatólogos ou quaisquer outros perdem todo o sentido.

Em síntese, se a antropologia sociocultural que pretende discutir com as biociências não estiver disposta a efetivamente realizar o movimento múltiplo de conhecer profundamente as questóes, as pesquisas e os debates, perpetuará seu monólogo. E se, depois disso, não fizer um mergulho profundo no conhecimento antropológico a fim de encontrar elementos para reflexão e, por fim, trazer contribuiçôes e rever os pontos necessários, qual o sentido do exercício? Será preciso quebrar os ovos para fazer o omelete!

\section{Notas}

1 Pinker (1999) produziu reflexões importantes sobre a modularidade da mente humana, e McBrearty e Brooks (2000) adotaram visão oposta.

2 Do inglês "punctuated equilibrium", capengamente traduzido no Brasil para "equilíbrio puntuado”.

3 Ver D'Errico et al. (1998) para uma visão distinta. 


\section{Bibliografia}

ADES, C.

1997 "O morcego, outros bichos e a questão da consciência animal”, Psicologia USP,

São Paulo, vol. 8(2), p. 129-57.

ALVARD, M. S.

2003 "The adaptative nature of culture", Evolutionary Anthropology, vol. 12, p. 136-49.

ARNOLD, K. \& WHITEN, A.

2001 "Post-conflit behaviour of wild chimpanzees (pan troglodytes schweinfurthii) in the Bundongo Forest, Uganda”, Behaviour, vol. 138, p. 649-90.

ARSUAGA, J. L.

2005[1999] O colar do neandertal: em busca dos primeiros pensadores, São Paulo, Globo.

ASQUITH, P. J.

1995 "Of monkeys and men: cultural views in Japan and the West", in CORBEY, R.

\& THEINISSEN, B. (eds.). Ape, man, apeman: changing views since 1600, Leiden, Dept. of Prehistory, Leiden University, p. 309-18.

AURELLI, F. \& DE WALL, F. B. M. (ed.)

$2000 \quad$ Natural conflict resolution, Berkeley/Los Angeles, University of California Press.

BAKER, K. C. \& AURELI, F.

2000 "Coping with conflict during initial encounter in chimpanzees", Ethology, vol. 106 , p. $527-41$.

BAKER, K. C. \& SMUTS, B. S.

2001

"Social relationships of female chimpanzees: diversity between captive social groups", in WRANGHAM, R. et. al. (eds.). Chimpanzee cultures, Chicago, Harvard University Press/Chicago Academy of Sciences.

BAKER, K. C. ET AL.

2000 "Injury risks among chimpanzees in three housing conditions", American Journal of Primatology, vol. 51(3), p. 161-75. 
Revista de Antropologia, São Paulo, USP, 2005, v. 48 № 2.

BALANDIER, G.

1974 Antropo-lógicas, São Paulo, Cultrix/Edusp.

BAR-YOSEF, O.

2002

"The upper paleolithic revolution", Annual Review of Anthropology, vol. 31, p. 363-93.

BETZIG, L.

1997

"People are animals", in BETZIG, L. (ed.). Human nature: a critical reader, New York, Oxford University Press.

BOEHM, C.

2001

"Pacifying interventions at Arnhem Zoo and Gombe", in WRANGHAM, R. W. et. al. (eds.), Chimpanzee cultures, Chicago, Harvard University Press/Chicago Academy of Sciences.

BÖESCH, C.

1991

“Teaching among wild chimpanzees", Animal Behavior, vol. 41, p. 530-32.

BÖESCH, C. \& TOMASELLO, M.

1998 "Chimpanzee and human cultures", Current Anthropology, vol. 39, p. 591-614.

BOYD, R. \& RICHERSON, J. P.

1995 "Why does culture increase human adaptability", Ethology and Sociobiology, vol. 16 , p. $125-43$.

BOYD, R. \& SILK, J. B.

2006 How humans evolved, Los Angeles, University of California.

BOURDIEU, P.

1989 O poder simbólico, Rio de Janeiro, Bertrand Brasil.

BUIRSKI, PLUTCHIK \& KELLERMAN

1978 "Sex differences, dominance, and personality in the chimpanzee", Animal Behavior, vol. 26(1), p. 123-29. 
CHENEY, D. L. \& SEYFARTH, R. M.

$1990 \quad H o w$ monkeys see the world, Chicago, University of Chicago Press.

CORBEY, R.

1995

"Introduction: missing links, or the ape's place in nature", in CORBEY, R. \& THEYNISSEN, B. (eds.). Ape, man, apeman: changing views since 1600, Leiden, Dept. of Prehistory, Leiden University, p. 1-10.

CRONK, L.; CHAGNON, N. \& IRONS, W. (eds.)

$2000 \quad$ Adaptation and human behavior: an anthropological perspective, New York, Walter de Gruyter.

DAMÁSIO, A.

2000 O mistério da consciência, São Paulo, Companhia das Letras.

DARWIN, C.

2001

A expressão das emoções no homem e nos animais, São Paulo, Companhia das Letras.

D'ERRICO, F.

2003

"The invisible frontier. A multiple species model for the origin of behavioral modernity", Evolutionary Anthropology, vol. 12, p. 188-202.

D’ERRICO, F.; ZILHÃO, J.; JULIEN M.; BAFFIER, D.; PELEGRIN, J.

1998 "Neanderthal acculturation in Western Europe?", Current Anthropology, vol. 39, p. $1-44$.

DE WAAL, F. B. M.

2000

Chimpanzee politics: power and sex among apes, Baltimore, The Johns Hopkins University Press.

2001 "Chimpanzee's adaptative potencial: a comparison of social life under captive and wild conditions", in WRANGHAM, R. W. et. al. (eds.). Chimpanzee cultures, Cambridge, Havard University Press/The Chicago Academy of Sciences, p. 243-62.

2001a "Overview. Culture and cognition", in WRANGHAM, R. W. et. al. (eds.). Chimpanzee cultures, Cambridge, Havard Univeristy Press/The Chicago Academy of Sciences, p. 263-66. 
Revista de Antropologia, São Paulo, USP, 2005, v. 48 No 2.

2005

"A century of getting to know the chimpanzee", Nature, vol. 437, p. 56-59.

DUKELOW, R. W.

1999

"Invited editorial: reflections on a century of primatology", American Journal of Primatology, vol. 49, p. 129-32.

DUNBAR, R.

Grooming, gossip and the evolution of language, Edinburg, Word Power Books.

DURHAM, E. R.

2003

"Chimpanzés também amam: a linguagem das emoções na ordem dos primatas”, Revista de Antropologia, vol. 45(1), p. 85-154.

DURHAM, W.

1991 Coevolution, genes, culture and human diversity, Pala Alto, Stanford University Press.

ELDREDGE, N.; GOULD, S. J.

1972 "Punctuated equilibria: An alternative to phyletic gradualism", in SCHOPF, T. J. M. (ed.). Models in paleobiology, São Francisco, Cooper \& Co., p. 82-115.

ELDREDGE, N.; GOULD, S. J.; COYNE, J. A.; CHARLESWORTH, B.

1997 "On punctuated equilibria", Science, vol. 276, p. 337-41.

FOLADORI, G.

2000

"O comportamento humano em relação a seu ambiente, à luz das teorias biológicas da evolução”, Acta Scientiarum, vol. 22(2), p. 327-35.

FOLEY, R.

1997 Humans before humanity: an evolutionary perspective, Oxford, Blackwell Publisher.

FOUTS, R.

1998

O parente mais próximo. O que os chimpanzés me ensinaram sobre quem somos, Rio de Janeiro, Objetiva.

FRAGASZY, D.

2003

“Making space for traditions", Evolutionary Anthropology, vol. 12, p. 61-70. 
GALEF, B. G.

"The question of animal culture", Human Nature, vol. 3, p. 157-78.

GEERTZ, C.

1978[1973] A interpretação das culturas, Rio de Janeiro, Zahar.

$2000 \quad$ Local knowledge, New York, Basic Books.

GOODALL, J.

1965

"Chimpanzees of the Gombe Stream Reserve", in DE VORE, I. (ed.). Primate behavior: field studies of monkeys and apes, New York, Holt, Rinehart and Winston.

1986 The chimpanzees of Gombe, patterns of behavior, Cambridge, Belknap Press of Harvard University.

1991 Uma janela para a vida: 30 anos com os chimpanzés da Tanzânia, Rio de Janeiro, Zahar.

2000 In the shadow of man, New York, Mariner Books.

HAUSER, M.

2005

"Our chimpanzee mind", Nature, vol. 437, p. 60-63.

HEBB, D. O.

1946

"Emotion in man and animal: An analysis of the intuitive processes of recognition”, Psychological Review, vol. 53, p. 88-106.

HENRICH, J. \& McELREATH, R.

2003 "The evolution of cultural evolution", Evolutionary Anthropology, vol. 12, p. $123-35$.

HENSHILWOOD, C. S.; D'ERRICO, F.; VANHAEREN, M.; van NIEKERK, K.; JACOBS, Z. 2004 "Middle stone age shell beads from South Africa", Science, vol. 304, p. 404.

HENSHILWOOD, C. S.; D'ERRICO, F.; YATES, R.; JACOBS, Z.; TRIBOLO, C.; DULLER, G. A. T.; MERCIER, N.; SEARLY, J. C.; VALLADAS, H.; WATTS, I.; WINTLE, A. G.

2002 "Emergence of modern human behavior: Middle Stone Age engravings from South Africa", Science, vol. 295, p. 1.278-80. 
Revista de Antropologia, São Paulo, USP, 2005, v. 48 no 2.

HOOF, J. Van

2001

"Understanding chimpanzee understanding", in WRANGHAM, R. W. et. al. (eds.). Chimpanzee cultures, Chicago, Harvard University Press/Chicago Academy of Sciences.

HRDY, S. B.

2001

Mãe natureza, Rio de Janeiro, Campus.

INGOLD, T.

1995

"'People like us': the concept of the anatomically modern human", in CORBEY, R. \& THEUNISSEN, B. (eds.). Ape, man, apeman: changing views since 1600, Leiden, Dept. of Prehistory, Leiden University, p. 241-62.

1996

"Debate: human worlds are culturally constructed. Against the motion (1)", in

INGOLD, T. (ed.). Key debates in anthropology, London/New York, Routledge.

JAHME, C.

2001

Beauty and the beasts: woman, ape and evolution, London,Virago.

JOULIAN, F. 1996

"Comparing chimpanzee and early hominid techniques: some contributions to cultural and cognitive questions", in MELLARS, P. A. \& GIBSON, K. A. (eds.). Chimpanzee cultures, McDonald Institute for Archaeological Research, p. 173-89.

KLEIN, R. G.

1999

Human career: human biological and cultural origins, Chicago, The University of Chicago Press.

2000 "Archaeology and the evolution of human behavior", Evolutionary Anthropology, vol. 9, p. 7-36.

KLEIN, R. G. \& EDGAR, B.

2005[2002] O despertar da cultura: a polêmica teoria sobre a origem da criatividade humana, Rio de Janeiro, Jorge Zahar.

KOLB, B. \& WHISHAW, I. Q.

2001

An introduction to brain behavior, New York, Worth Publisher. 
KUPER, A.

The choosen primate, Cambridge, Harvard University Press.

2000

"If memes are the answer, what is the question?", in AUNGER, R. (ed.).

Darwinising culture: the status of memetics as a science, Oxford, Oxford Universi-

ty Press, p. 175-88.

LADYGINA-KOHTS, N. N.

2002[1935] Infant chimpanzee and human child: a classic 1935 comparative study of ape emotions and intelligence, Oxford, Oxford University Press.

LAHR, M. M. \& FOLEY, R. A.

1994

"Multiple dispersions and modern human origin", Evolutionary Anthropology vol. 3, p. 48-60.

LEAVENS, D. A.; AURELI, F. \& HOPKINS, W. D.

2004

"Behavioral evidences for the cutaneous expression of emotion in chimpanzee (Pan Troglodytes)”, Behavior, vol. 141(8), p. 79-97.

LESTEL, D.

2004

L'animal singulier, Paris, Seuil.

LÉVI-STRAUSS, C.

1982 As estruturas elementares do parentesco, Petrópolis, Vozes.

1988 O pensamento selvagem, Campinas, Papirus.

1993 Antropologia estrutural dois, Rio de Janeiro, Tempo Brasileiro.

LEWIN, R.

2005

Human evolution: an illustrated introduction, Oxford, Blackwell Publishing.

LYDDY, F.

2002

"Lateral bias in chimpanzee expressions of facial emotion", Trends in Cognitive Sciences, vol. 6(9), p. 369.

LINDLY, J. M. \& CLARK, G. A.

1990 "Symbolism and modern human origins", Current Anthropology, vol. 31(3), p. 233-61. 
LOCK, A.

2000

"On the recent origin of symbolically-mediated language and its implications for psychological science”, in CORBALLIS, M. C. \& LEA, S. E. G. (eds.). The descent of mind: psychological perspectives on hominid evolution, New York, Oxford University Press, p. 324-55.

MARCUS, G. \& FISCHER, M. M. J.

1999

Anthropology as cultural critique, Chicago, University of Chicago Press.

MARCUS, G. \& MYERS, F. R. (eds.)

1995 The traffic in culture: refiguring art and anthropology, California, University of California Press.

MARKS, J.

2002

What it means to be 98\% chimpanzee? Apes, people, and their genes, Berkeley/ Los Angeles, University of California Press.

MASON, W. A. \& MENDONZA, S. P. (eds.)

1993

Primate social conflict, Albany, State University of New York Press.

MASSENZIO, M. \& LÉVI-STRAUSS, C.

2001 "An interview with Claude Lévi-Strauss", Current Anthropology, vol. 42(3), p. 419-25.

MAUSS, M.

1974 Sociologia e antropologia, São Paulo, EPU/Edusp, 2v.

McBREARTY, S. \& BROOKS, A. S.

2000 "The revolution that wasn't: a new interpretation of the origin of modern human behavior", Journal of Human Evolution, vol. 39, p. 453-563.

McDOUGALL, I.; BROWN, F. H. \& FLEAGLE, J. G.

2005 "Stratigraphic placement and age of modern humans from Kibish, Ethiopia", Nature, vol. 433, p. 733-36.

McGREW, W. C.

1996 Chimpanzee material culture, Cambridge, Cambridge University Press. 
MELLARS, P.

2003 "Symbolism, meaning and the Neanderthal mind", Cambridge Archaeological Journal, vol. 13, p. 273-75.

2005 "The impossible coincidence. A single-species model for the origin of modern human behavior in Europe", Evolutionary Anthropology, vol. 14, p. 12-27.

MITANI, J. C.; WATTS, D. P. \& MULLER, M. N.

2002 "Recent developments in the study of wild chimpanzee behavior", Evolutionary Anthropology, vol. 11, p. 9-25.

MITCHELL, R. W. \& HAMM, M.

1997 "The interpretation of animal psichology: anthropomorphism or behavior reading?”, Behavior, 134, p. 173-204.

MITHEN, S.

2002[1996] A pré-história da mente: uma busca das origens da arte, da religião e da ciência, São Paulo, Ed. Unesp.

MORRIS, D.

1967 The naked ape, New York, Dell Publisher Co.

PARKER, S. T. \& GIBSON, K. R.

1994 "Language" and intelligence in monkeys and apes, Cambridge, Cambridge University Press.

PAVELKA, M. S. M.

2002

"Change versus improvement over time and our place in nature", Current Anthropology, vol. 43 (supplement), p. S37-S44.

PINKER, S.

1999[1997] Como a mente funciona, São Paulo, Companhia das Letras.

2004[2002] Tábula rasa: a negação contemporânea da natureza humana, São Paulo, Companhia das Letras.

RABINOW, P. \& SULLIVAN, W. M. (eds.)

1979

Interpretative social science: a reader, Berkeley, University of California Press. 
RAPCHAN, E. S.

2004

"Os parentes de nossos parentes: um ensaio sobre a sociedade e as culturas dos chimpanzés sob uma perspectiva antropológica”, Revista de Etologia, vol. 6(2), p. 101-17.

2005 "Chimpanzés possuem cultura? Questões para a antropologia sobre um tema bom para pensar”, Revista de Antropologia, vol. 48(1) , p. 227-80.

RODMAN, P. S.

1999

"Whither primatology? The place of primates in contemporary anthropology", Annual Review of Anthropology, 28, p. 311-39.

RUMBAUGH, D. M.; SAVAGE-RUMBAUGH, E. S. \& SEVCIK, R. A.

2001

"Biobehavioral roots of language: a comparative perspective of chimpanzee, child and culture", in WRANGHAM, R. W. et. al. (eds.). Chimpanzee cultures, Chicago, Harvard University Press/Chicago Academy of Sciences, p. 319-34.

SANGREN, P. S.

1988

"Rethoric and the authority of ethnography: "postmodernism" and the social reproduction of texts", Current Anthropology, vol. 29(3), p. 405-35.

SAPOLSKY, R. M.

2004

"Social status and health in humans and other animals", Annual Review of Anthropology, vol. 33, p. 393-418.

SAVAGE-RUMBAUGH, S. \& LEWIN, R.

1994 Kenzi, the ape at the brink of human mind, New York, John Wiley \& Sons.

SAVAGE-RUMBAUGH, S.; FIELDS, W. M. \& TAGLIATELA, J. P.

2001 "Language, speech, tools and writing. A cultural imperative", Journal of Consciouness Studies, vol. 8(5-7), p. 273-92.

SMITH, E. A.

2000

"Three styles in the evolutionary analysis of human behavior", in CRONK, L.; CHAGNON, N. \& IRONS, W. (eds.). Adaptation and human behavior: an anthropological theory, New York, Aldine and Gruyer, p. 27-46. 
SPERBER, D.

O simbolismo em geral, São Paulo, Cultrix.

1985

"Anthropology and psychology: towards an epidemiology of representations", Man, vol. 20(2), p. 73-89.

$1992 \quad O$ saber dos antropólogos, Lisboa, Ediçōes 70.

2000 "An objection to the memetic approach to culture", in AUNGER, R. (ed.). Darwinizing culture: the status of memetics as a science, Oxford, Oxford University Press, p. 163-73.

STANFORD, C. B.

1998 "The social behavior of chimpanzees and bonobos", Current Anthropology, vol. 39, p. 399-420.

2001 Significant others: the ape-human continuum and the quest for human nature, New York, Basic Books.

STEARNS, S. C. \& HOEKSTRA, R. F.

2003 [2000] Evolução: uma introdução, São Paulo, Atheneu Editora São Paulo.

STOCKING, G. W.

1982 Race, culture, and evolution, Chicago, University of Chicago Press.

STRAUS, L. G.

"The upper paleolithic of Cantabrian Spain", Evolutionary Anthropology, vol. 14 , p. $145-58$.

STRINGER, C.

African exodus: the origins of modern humanity, New York, Holt.

SUGIYAMA, Y.

"Social tradition and the use of tool-composites by wild chimpanzees", Evolutionary Anthropology, vol. 6, p. 23-27.

TOMASELLO, M.

1994

"Cultural transmission in the tool use and communicatory signaling of chimpanzees?", in PARKER, S. T. \& GIBSON, K. R. (eds.). "Language" and intelligence in monkeys and apes, Cambridge, Cambridge University Press. Primate cognition, Oxford, Oxford University Press. 
Revista de Antropologia, São Paulo, USP, 2005, v. 48 № 2.

1999

The cultural origins of human cognition, Cambridge, Harvard University Press.

TOMASELLO, M. \& CALL, J.

1997 Primate cognition, New York/Oxford, Oxford University Press.

TOOBY, J. \& COSMIDES, L.

1992 "The psychological foundations of culture", in BARKOW, J. et. al. (eds). The adapted mind, Oxford, Oxford University Presses.

TOTH, N.; SCHICK, K. D.; SAVAGE-RUMBAUGH, D. M.; SEVICK, R. A. \& RUMBAUGH, D. M.

1993

"Pan the tool-maker: Investigations into the stone tool-making and tool-using capabilities of a bonobo (Pan paniscus)", Journal of Archaeological Science, vol. 20, p. 81-91.

TURNER, V.

2005[1969] A floresta de simbolos, Niterói, Ed. UFF.

TUTTLE, R. H.

2001 "On culture and traditional chimpanzees", Current Anthropology, vol. 42, p. $407-8$.

YELLEN, J. E.; BROOKS, A. S.; CCORNELISSEN, E.; MEHLMAN, M. J. \& STEWART, K. 1995

"A middle stone age worked bone industry from Katanda, Upper Semliki Valley, Zaire", Science, vol. 268, p. 553-56.

WHITEN, A.; GOODALL, J.; McGREW, W. C.; NISHIDA, T.; REYNOLDS, V.; SUGIYAMA, Y.; TUTIN, C. E. G.; WRANGHAM, R. W. \& BOESCH, C.

1999 "Cultures in chimpanzees", Nature, vol. 399, p. 682-85.

WILSON, M. L. \& WRANGHAM, R.W.

2003 "Intergroup relations in chimpanzees", in DURHAM, W. D. (ed.). Annual Review of Anthropology, vol. 32, p. 363-92.

WINTERHALDER, B. \& SMITH, E. A. (eds.)

1992 Evolutionary ecology and human behavior, New York, Aldine de Gruyter Inc. 
WRANGHAM, R. W; McGREW, W. C.; de WAAL, F. B. M. \& HELTNE, P. (eds.) Academy of Sciences.

WRANGHAM, R. W. \& PETERSON, D.

\begin{abstract}
This article is the product of a critical scrutiny of "Chimpanzés também amam: a linguagem das emoções na ordem dos primatas", by Eunice Durham. Our comprehensive critical review of Durham's work reflects the importance of her article in the Brazilian anthropological context. For the first time in the country issues related to human evolutionary behavioral ecology, neurobiology, evolutionary psychology, and sociobiology, albeit naïvely, were raised by a distinguished local anthropologist traditionally affiliated to the symbolic school under a positive perspective. Durham's contribution is critically scrutinized in this paper following two main perspectives: the danger of representational bias contaminating those engaged in long term studies of great apes social behavior, and the danger to assume that human-like behaviors presented by these large primates can be seen as homologous to ours. Although we concur with Durham that evolutionary theory can be of great importance in the study of human social behavior, the preeminence of meaning behind behavior is stressed here as a unique property of Homo sapiens.
\end{abstract}

KEY-WORDS: chimpanzee, emotions, evolution, feelings, symbol. 